Portland State University

PDXScholar

1984

\title{
Lesbianism in sport from the perspective of the female team sport college athlete and the female team sport recreational player
}

Tracy Laura Jaynes

Portland State University

Follow this and additional works at: https://pdxscholar.library.pdx.edu/open_access_etds

Part of the Health and Physical Education Commons, and the Lesbian, Gay, Bisexual, and Transgender Studies Commons

Let us know how access to this document benefits you.

\section{Recommended Citation}

Jaynes, Tracy Laura, "Lesbianism in sport from the perspective of the female team sport college athlete and the female team sport recreational player" (1984). Dissertations and Theses. Paper 3335.

https://doi.org/10.15760/etd.3315

This Thesis is brought to you for free and open access. It has been accepted for inclusion in Dissertations and Theses by an authorized administrator of PDXScholar. Please contact us if we can make this document more accessible: pdxscholar@pdx.edu. 
AN AESTRACT OF THE THESIS OF Tracy Laura Jaynes for the Master of Science in Teaching in Physical Education presented February 17, 1984.

Title: Lesbianism in Sport From the Perspective of the Female Team Sport College Athlete and the Female Team Sport Recreational Player.

APPROVED BY MEMBERS OF THE THESIS COMMITTEE:

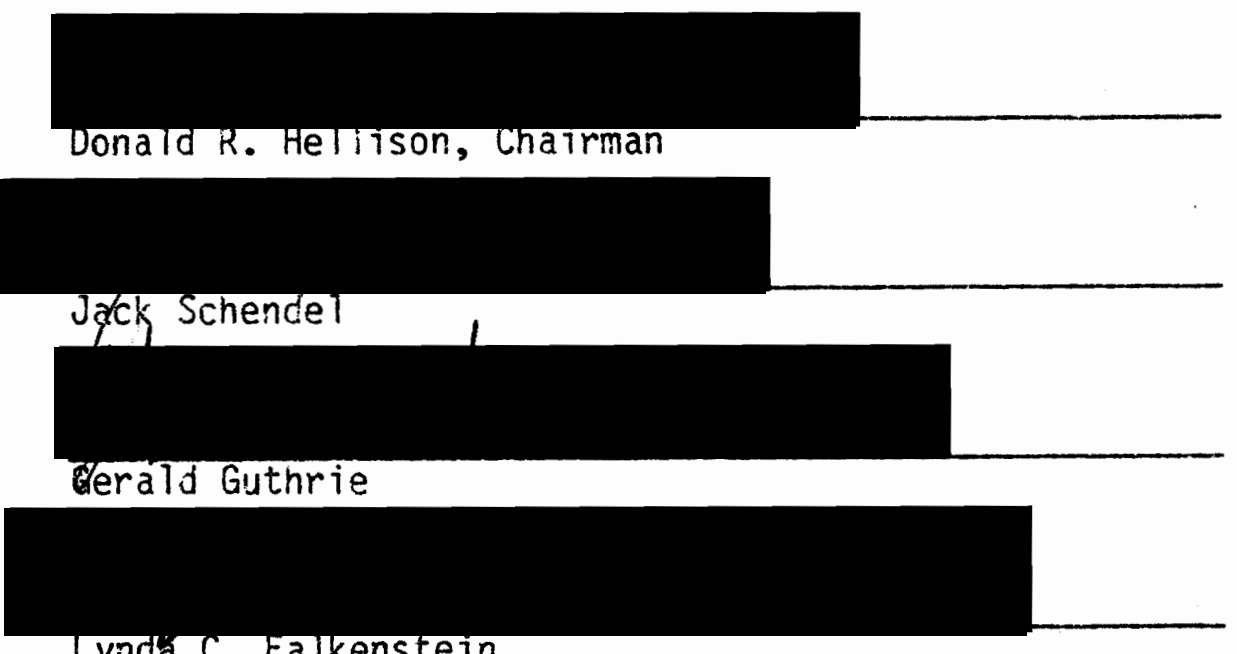

Lyndá c. Falkenstein

This study was designed to determine the degree of homophobia, expressed lesbian sexual preference behavior, and attitudes toward lesbianism among the female team sport college athilete and the female team sport recreational player. It was hypothesized that the female tean sport college athlete would be less homophobic, would express greater lesbian! sexual preference behavior, and wouid possess mcre positive attitudes toward lesbianism than the female team spcrt recreational player. There Were 32 female team sport college athletes representing four Utah university/collece campuses and one Ciegon university/college campus; 37 female team sport recreational piayers representing four Utan recreational team and two Oregon recreationa? teams. 
Data were collected during the months of March through June, 1983. A11 subjects participating were volunteers. The subjects' ages ranged from 18-35, the mean age being 23.5 years.

The instruments used in this study were: 1) Index of Attitudes Toward Lesbians (Guthrie, 1982), 2) Demographic/Social Variable Data (Guthrie, 1982). The research administered the instruments individually to each volunteer, therefore there was a $100 \%$ return.

Chi-Square Analyses were used and the major results indicated that there were no significant differences in the degree of homophobia, lesbian sexual preference behavior, and positive attitudes toward lesbianism between the two groups.

Post hoc analyses of data were performed to determine whether age was a factor in degree of homophobia, the expression of lesbian sexual preference behavior, and the expression of positive attitudes toward lesbianism. These analyses revealed a large percentage of those individuals in the age group 20-24 years expressed non-homophobia, lesbian sexual preference behavior, and positive attitudes towards lesbianism. Since this age group (20-24 years) encompasses a great proportion of the college age women who participate in athletics, it is hypothesized that exposure, involvement, and attitudes concerning lesbianism are noticeably prevalent in the college athletic environment. 
LESBIANISM IN SPORT FROM THE PERSPECTIVE OF THE FEMALE TEAM SPORT COLLEGE ATHLETE AND THE FEMALE TEAM SPORT RECREATIONAL PLAYER

by

TRACY LAURA JAYNES

A thesis subinitted in partial fulfillment of the requirements for the degree of

MASTER OF SCIENCE IN TEACHING

in

PHYSICAL EDUCATION

Portlard State University

1984 
TO THE OFFICE OF GRADUATE STUDIES AND RESEARCH:

The members of the Committee approve the thesis of Tracy Laura Jaynes presented February 17, 1984.

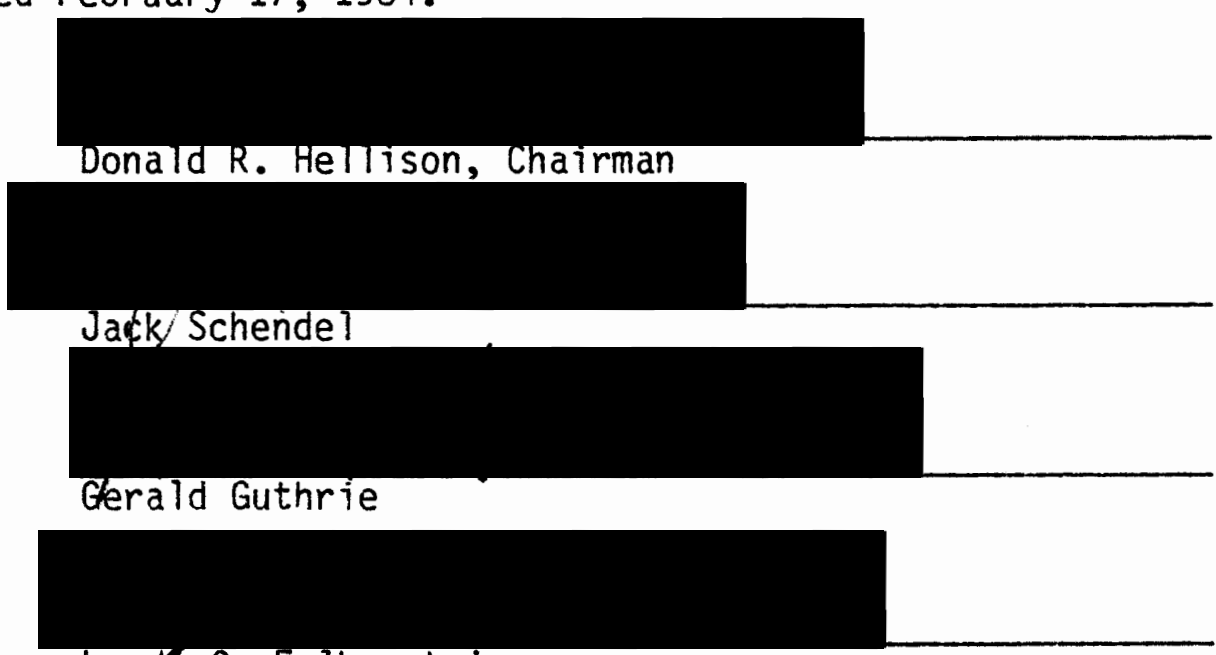

Lynda c. Falkenstein

APPROVED:
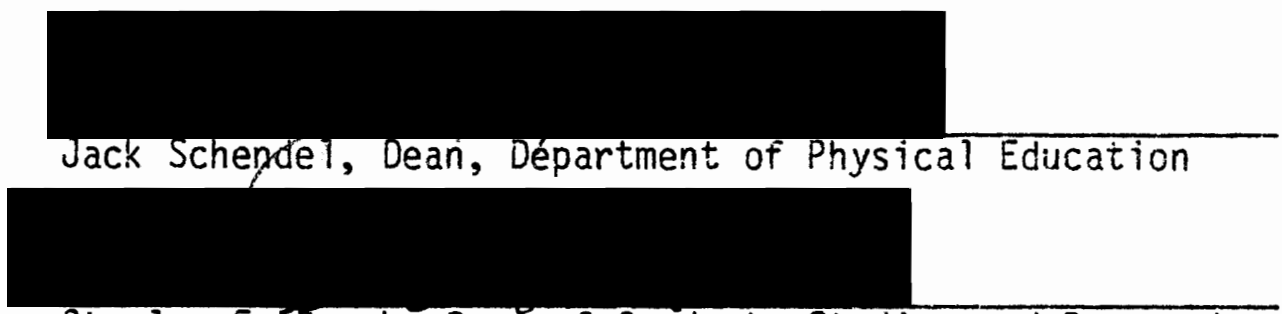

Stanley E. Rauch, Deañ of Graduate Studies and Research 


\section{ACKNOWLEDGEMENTS}

My gratitude and thanks is extended to Dr. Donald Hellison, for giving me the freedom to investigate this issue despite the odds.

Thanks is extended to my committee members; Dr. Jack Schendel, Dr. Gerald Guthrie, and Dr. Lynda Falkenstein for their time and efforts.

A special thanks is extended to the following people, for without their help my thesis wouldn't have been completed. Jerilyn Wakefield, for her time and skills in editing; Ron Hill, for his assistance with the statistics and Kathy Chisholm for her professional typing of the final draft.

Lastly, much appreciation goes to the athletes who participated in the study for without them the study wouldn't have been possible. 
TABLE OF CONTENTS

PAGE

ACKNOWLEDGEMENTS

LIST OF TABLES

CHAPTER

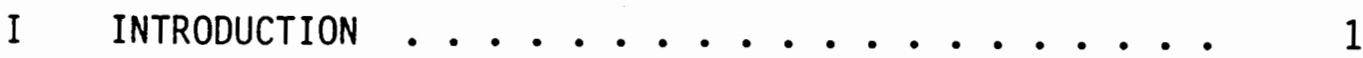

Statement of the Problem ......... 6

Significance of the Problem ........ 7

Statement of the Hypotheses ........ 7

Delimitations ................. 7

Definitions of Terms ......... 8

II REVIEW OF RELATEd LITERATURE . . . . . . . 10

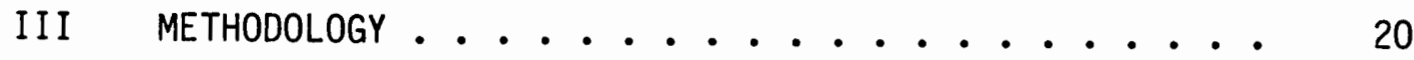

Sample Description ........... 21

Instrumentation .............. 22

Procedure ................ 24

Analysis of the Data.......... 25

IV ANALYSIS OF DATA ..................... 26

$\checkmark$ SUMMARY AND CONCLUSIONS ......................... 34

Restatement of Problem ......... 34

Major Findings ............. 34

Conclusions ................... 36

Final Observations .............. 37

REFERENCES ........................ 40

APPENDICES ............................ 47 
TABLE

PAGE

I A Comparison of Female Team Sport College Athletes

Female Team Sport Recreational Players by Age . . . 21

II Categorical Scores of Homophobia Between Female Team

Sport College Athletes and Female Team Sport

Recreational Players ........... 27

II Sexual Preference Behavior of Female Team Sport College

Athletes and Female Team Sport Recreational Players • 28

IV A Comparison of Attitudes Toward Lesbianism Between

Female Team Sport College Athletes and Female Team

Sport Recreational Players . . . . . . . 29

$\checkmark$ First Exposure of Sexual Intimacy Between Women from

Female Team Sport College Athletes and Female Team

Sport Recreational Players . . . . . . . . 31 


\section{INTRODUCTION}

In order to shed some light on lesbianism in organized sport and to show the need for educating society about different life styles, this exploratory descriptive study was undertaken. Current trends suggest that American society is moving towards a sports oriented population. Along with this movement, the acceptance of different life styles has occurred, including the approval of physical activity for women. According to Greendorfer (1978), sport for women represents a fast growing and changing element in American culture today. There is little question that this interest and momentum will continue to expand competitive sport opportunities for women as well as promote a greater need for understanding the psychological and sociological responses of women to athletic competition.

Neal (1978) suggests that the main reason that American women have had scant interest in sports in the past is that cultural taboos have decreased any natural motivation they might have had to engage in competitive activities. Society has forced women to adhere to the "normal" female sex-role and assume the stereotype that it demands: marrying, raising a family, and being a good housekeeper. The majority of women who do engage in sports experience a role conflict by entering the male dominated realm of sports. Numerous researchers (DelRey, 1978; Gerber, 1974; Harris, 1979; Hart, 1976; Hart, 1980; \& Kort, 1979) have noted that to be an athlete and female are contradictory social statuses with conflicting role expectations. 
According to Hart (1980) the female athlete has met more oppression than almost all other women in American society. Being involved in sports she adopts the role of woman athlete, and, accordingly, is perceived as possessing all the "unsavory" characteristics of the active and powerful woman. The female athlete is seen as intelligent, competitive, aggressive, and strong (Hart, 1980). While these traits are desirable for success in the sports area, they appear to be of much less value to a woman in the social world outside of sports. Brooks (1981) and Hart (1976) have both indicated that these traits may be not only of less value in the social world but indeed bring stigma to a woman. The female athlete would then seem to be forced by cultural definitions to choose between being an athlete and being a conventional woman. This dichotomy illustrates the dissonance between society's stereotypic view of acceptable female behavior and the qualities necessary for successfui participation in a competitive sport.

Despite this dissonance more women are competing in sports, especially at the college and recreational level throughout the country. Along with the surge of participation at the college level, new demands from society have changed the entire perspective of athletics for women. There is now an increased demand from administrators to produce winning teams. Athletic directors are putting greater pressure upon coaches and players to produce a winning season. Coaches are expected to gear their programs toward becoming national contenders and as a result sports are becoming year round activities on most college or university campuses. Female athletes are expected to participate in a preseason period with 
emphasis on skills, physical conditioning, and strategies. A competitive period involving practice and playing an average of 25-30 games or matches depending upon the sport as well as a postseason period emphasizing maintenance of conditioning principles and work on deficient skill areas. This intensive regime has created many new psychosocial dilemmas for the coaches and the players.

It is possible that through competition the female athlete has developed a strong personality and a sense of self sufficiency, and she may not even be aware at the time that the physical and psychological strength and courage rewarded in athletics are in glaring conflict with the femininity that is rewarded socially. According to Abbott \& Love (1972) if she happens to leave the sports world she learns quickly that she is not considered feminine if she continues to be competitive or aggressive and independent. Wughalter (1978) stated that many female athletes have minimized the potential for such psychological conflicts by immersing themselves entirely in the sports world. These athletes have surrounded themselves with students, friends, coaches, and employers who have higher expectations of the sports role than any "feminine" role. By rarely leaving the playing field, the female athlete satisfies her career goals with a minimum of social conflict.

The process of conquering the sex-role conflict--female athlete versus the stereotypic "feminine" woman--occurs primarily among women in the 18-22 age group and includes the majority of college age women who do participate in athletics. During this period of their lives most young adults are marrying or forming some other kind of relatively enduring sexliaison. They are defining themselves in terms of their adult "masculine" and "feminine" roles (Maccoby \& Jacklin, 1978, cited in Birrell, 1978). 
Besides the issue of femininity the issue of lesbianism has often been associated with the female athlete (Elkins, 1978; Guthrie, 1982; Hart, 1980; Hicks, 1979; Kennard, 1977; Klaich, 1974; \& Wughalter, 1978). In a culture in which competitive and aggressive behavior appears to detract from a woman's "femininity", women athletes, especially those who participate in team sports, become prime targets for insinuations concerning their sexual preference. Team sports traditionally have been viewed as "masculine" (Snyder \& Spreitzer, 1978) and female athletes participating in the so-called "masculine" team sports are more likely to be stereotyped as lesbians (Guthrie, 1982). Sage \& Loudermilk (1979) found that female athletes who participated in traditionally socially unapproved sports, in this case team sports, experienced greater sex-role conflict than athletes who participated in more socially approved individual sports.

There are numerous theories as to the causes and occurrences of lesbianism. It is not justifiable to examine the "causes" of homosexuality without looking at the "causes" of heterosexuality. Often times our perception of what is "natural" is a product of socialization. What should be addressed is the need of human interaction as a vital and life sustaining necessity for a11. Sports participation provides an avenue for human interaction to take place. This interaction may take many forms depending upon the needs expressed by the player or group. Both men and women have a need for this interaction and subsequently a desire to satisfy their affiliative needs.

Because of the length of time spent together, with shared pressures, discouragements, and achievements, athletes are likely to 
form close bonds with one another. When much is shared together, much seems to be felt together. Teams win and lose, laugh and cry, hope and despair--all together as a team. As they work with each other, they feel emotionally for each other (Neal, 1972). Deaux (1976) stated that women more so than men have a strong propensity for same-sex pairing, resulting in much stronger bond formation. Women are comfortable being close to one another and female athletes might be victims of their own feminine sex-role stereotypes. The stereotype allows them more freedom to express their feelings of friendship and affection for members of their own sex and to them affiliation means getting emotionally closer to people (Chafetz, 1974; Money \& Tucker, 1975).

Hyde (1982) has proposed that human beings are naturally attracted to people with whom they have had contact many times and who give them positive reinforcement. Thus, the total involvement aspect with sports is potentially very personal and intimate, and as such, an individual can perhaps more easily become involved with others on a level other than "play". As Neal (1972) has suggested, the personal, intimate feeling that the female athlete has toward the play involvement becomes a close, intimate, binding relationship with others who share the same play experience. Similarly Hicks (1979) suggested that a female athlete's lesbianism could have a great deal to do with the talent, courage, and dedication which spurs her to seek out the companionship of others with like capabilities and motivations.

As women athletes transcend their stereotypical roles, their femininity and sexual preference increasingly become questioned, and they become the targets of homophobic attack (Guthrie, 1982). Weinberg 
(1973) has conceptualized homophobia as the fear or intolerance of homosexuality, and Guthrie (1982) has suggested that homophobia hinders participation in activities such as athletics. Guthrie (1982) has suggested that the outcome of this attack on lesbian athletes' sexual preferences and the expressed homophobic behavior exhibited toward them by teammates leads many lesbians to deny, suppress, or hide their feelings from family, friends, work associates, and occasionally themselves. Guthrie (1982) also noted that the psychological toll of such a closeted life is extremely high in that the constant deception is a tremendous drain of energy and emotional reserve. If women choose to be athletes and choose to be lesbians, the psychological price of the facade they build can interfere with the development of their full potential. They are hiding from one another and hiding from the public. The energy spent playing these games could be better used in something that is more productive; the traveling, and competitive lifestyle associated with athletics is stressfur enough without the additional weight of the facade (Hicks, 1979).

Many heterosexual athletes deeply resent these attacks on their femininity and sexual preference and thus blame lesbian athletes for fostering this unfavorable image (Fairchild \& Hayward, 1977; Hicks, 1979). Such an attitude creates unnecessary friction and dissension among team members and ultimately reduces optimum player performance as well as undercuts the coaches' and players' goals. This study was designed to determine the degree of homophobia, expressed lesbian sexual preference behavior, and attitudes toward lesbianism among two groups: The female 
team sport college athlete who is committed to a nine month conditioning, practicing, and playing schedule and the female team sport recreational player who participates primarily for fun and socialization with peers and for whom conditioning, practicing, and playing are usually limited to one day a week. These two groups were studied in order to determine if a difference existed in the degree of homophobia, expressed lesbian sexual preference behavior, and attitudes toward lesbianism, based on the assumption that a difference does exist in the length of time each group spends conditioning, practicing, and playing together. Based on the literature, it is hypothesized that female team sport college athletes will be less homophobic, will express greater lesbian sexual preference, and will possess more positive attitudes toward lesbianism than female team sport recreational players. However, the data base for such hypotheses is so weak that no formal hypotheses are presented here. Instead, this study intends to explore attitudes and behavior in women's sport toward an eventual description of the current state of affairs.

\section{Delimitations}

This study deals specifically with female team sport athletes from selected schools and recreational teams whose players were 18 years of age or oider. Results should not be extended beyond this population. Also, because all of the women surveyed in this investigation were volunteers, the sample may not have been truly representative of even that group. These subjects may have been curious and/or interested in the research which may have affected their scores on the instruments and 
no means were available to confirm or deny this possibility. In addition, potential subjects may have failed to volunteer due to the sensitivity of the questions. Lastly, female team sport recreational players may have been college athletes at one time. This fact may have had an effect on their scores and responses because of the possibility of previous exposure to lesbianism while competing.

\section{Definition of Terms}

The following are the major concepts and their definitions referred to throughout this study:

Homophobia is the fear or intolerance of homosexuality and includes the emotional responses of disgust, anger, anxiety, discomfort, and/or aversion with respect to lesbians only. It does not include judgements concerning the morality of homosexuality, decisions regarding personal and social relationships and any other responses based on beliefs, preferences, legality, or social desirability. The term, then, refers to the degree of feeling comfortable or uncomfortable in various situations involving lesbians specifically as measured by the Index of Attitudes Toward Lesbians designed by Guthrie (1982).

Female Team Sport College Athlete is any female who participates in an intercollegiate team sport activity. She represents a college or university and is sometimes on scholarship for her efforts. The athlete is committed to an extensive conditioning, practicing, competing, and traveling program which runs the entire nine month school year.

Female Team Sport Recreational Player is any female who participates in a team sport activity primarily for fun and socialization with peers. 
She usually receives no monetary subsidy and pays for the majority of her expenses. Conditioning, practicing, competing, and traveling are usually limited to one day a week with the exception of tournament play and are not mandatory to participation.

Lesbian is a woman whose primary erotic, psychological, emotional, and social interest is in a member of her own sex, even though that interest may not be overtiy expressed as defined by Martin \& Lyon (1972). 


\section{REVIEW OF RELATED LITERATURE}

To date there has been little or no research investigating the issues of homophobia and sexual preference behavior among female athletes. A pioneering study dealing with homophobia and lesbians was completed in 1982 by Sharon Guthrie, a Master's degree student in physical education at Long Beach State University. Her study attempted to determine the degree of homophobia among female college athletes, physical education majors, and non-physical education majors, and to examine the effects of this phenonmenon on women in sports and physical education. However, it did not make any reference to the percentage of lesbian behavior among the populations.

Guthrie's study is the only one of its kind that measures homophobia pertaining specifically to lesbians. Also, it is the sole investigation employing the female college athlete as a studied population in this realm. Prior to this study all homophobic inquiries (Berry \& Marks, 1969; Brown \& Amoroso, 1975; Churchill, 1976; Hood, 1973; Hudson \& Ricketts, 1980; Lehne, 1976; Levitt \& Klassen, 1974; Lumby, 1976; \& Morin \& Garfinkle, 1978) were directed towarcis homosexuals in general, specifically the male population. To get a truer scale pertaining specifically to lesbians, Guthrie created the Index of Attitudes Toward Lesbians (IAL). The IAL is a 26 -item sumnated category partition scale which is a modified version of the original instrument developed by Hudson \& Ricketts (1980) and measures homophobia.

Guthrie's subjects consisted of 463 female college students gathered from five southern California campuses and one soutinern United 
States university. There were 122 athletes (non-majors); 50 athletes (physical education majors); 232 non-majors (non-athletes); and 59 physical education majors (non-athletes). All subjects were volunteers and came from general physical education classes and collegiate athletic teams. Subjects ranged in age from 17 to 45 with a mean age of 21.1 . Guthrie found that $69 \%$ of the respondents expressed homophobia (i.e., an IAL score of 51 or greater). In addition, $18 \%$ of the population was found to be high grade homophobic (i.e., an IAL score of 76 or greater) while only $8 \%$ was observed to be high grade non-homophobic (i.e., an IAL Score of 25 or less). The basis for these scores was derived from Hudson \& Ricketts's homophobia scale of 1980. A study done eight years prior to Guthrie's by Levitt \& Klassen (1974) found that 50 $\%$ of the 30,018 subjects expressed homophobia. The high percentage of homophobic responses among the two studies indicates that homophobia is still a part of the conventional American attitude concerning homosexuality in spite of the so-called "sexual revolution" that has taken place in the United States (Weinberg, 1973).

When comparing the four experimental groups in Guthrie's study according to the levels of homophobia, non-athletes were significantly more homophobic than athletes; and physical education majors were the least homophobic of all groups. Because women athletes and physical education majors have historically been target groups for identification as lesbians (Beach, 1981; Elkins, 1978; Guthrie, 1982; Hart, 1980; Hicks, 1979; Hoch, 1980; \& Kennard, 1977), they frequently have had to confront the myths and stereotypes surrounding such sexual orientations. 
Guthrie (1982) observed that increased exposure to the myths and stereotypes has led many of them to a greater level of awareness and understanding that these myths and stereotypes are unfounded and/or invalidated by their own life experiences. This observation is supported by Morin (1974) and Morin \& VanSharik (1975) who found changes in attitudes of students towards homosexuals after exposure to a course or single article on homosexuality.

Guthrie's study did not differentiate team sport athletes from individual sport athletes. However, Guthrie found a significant difference between sport preference of the groups in terms of their level of homophobia. Those female subjects who preferred individual sports were more homophobic than those who preferred team sports. This finding provides a high correlation between negative stereotyping of team sport athletes and perceived sexual preference behavior (Guthrie, 1982). Athletes who play team sports have traditionally been viewed as "masculine" (DelRey, 1978; Gerber, 1974; Guthrie, 1982; Harris, 1980; Hart, 1980; Hicks, 1979; Mathes, 1978; Sage \& Loudermilk, 1979; Snyder \& Spreitzer, 1978; \& Wughalter, 1978) and this perceived masculinity has been linked to perceived homosexuality (Abbott \& Love, 1972; Chafetz et al., 1974; Clark, 1977; Hyde, 1982; Klaich, 1974; Martin \& Lyon, 1972; Simpson, 1976; Storms et. al., 1981; Weinberg, 1973; \& Wolff, 1973). Storms et. al., (1981) suggested that people form detailed "scripts" or mental scenarios about the sexual behavior and attributes of men and women in various situations. A perceived association between sex role and sexual orientation often times was exaggerated and oversimplified, 
and influenced people's attitudes. They found that even when a woman was extremely "feminine" in appearance, mannerisms, and personality traits, the knowledge that she was homosexual led people to perceive her as more masculine. This might explain why the general population holds so tenaciously to the belief that homosexuals act like the opposite sex and those who exhibit opposite sex attributes are homosexual despite the likelihood that data for such beliefs are empirically weak.

Guthrie's study substantiated this assumption (i.e., team sports being more masculine, hence homosexual); volleyball being the only team sport that was not perceived as having a high percentage of lesbian participants. This coincides with Metheny's (1965) contention that volleyball is considered a socially acceptable sport for women because a spatial barrier (i.e., the net) prevents bodily contact with the opponenent in face-to-face competition.

The number of women who would define themselves as lesbians in this country remains an estimate. Brooks (1981) suggested that at least $10 \%$ of the adult female population are lesbians, whereas Simpson (1976) estimated a homosexual population of twenty million with the distribution of male/female homosexuals at half and half. Lesbianism has been much less studied than male homosexuality (Saghir \& Robins, 1973; \& Bullough \& Builough, 1977) and could account for the reason for the lack of demographic data. Those studies which have been done are centered around the notion that the deviant sexual commitment is the primary explanatory variable (Gagnon \& Simon, 1967). Systematic studies dealing with the behavioral characteristics and general attitudes of lesbians are lacking. Even more so, the studies concerning lesbianism 
in athletics are scarce despite the continual speculation and innuendos by society concerning the female athlete's sexual preference. Again, estimations abound throughout the literature on the percentage of lesbian and/or homosexual athletes. Snyder \& Spreitzer (1978) cited a 1976 Playboy survey of 3,700 male and female athletes which indicated that $8 \%$ of these athletes were exclusively homosexual. Fairchild \& Hayward (1977) stated that the proportion of gay women in amateur and professional sports was perhaps 3 to 4 times as great as in the population as a whole. Axthelm (1981) reported that there is a higher percentage of lesbians in sports than in 'real' life but it is neither 'rampant' nor a 'scandal' and its elimination is neither a likelihood nor a goal, in sports anymore than in life.

Do sports create lesbians, or do lesbians simply do better in sports because they, for the most part, are independent, psychologically strong, and self-sufficient? The traditional argument for not allowing women to participate in sports was that it promoted the development of masculine characteristics (e.g. aggressiveness, independence, self-sufficiency). In a society such as ours which for the most part demands strict adherence to the appropriate sex-roles, any female who steps beyond the narrow boundaries can hardly avoid being called masculine, since success and athletic talent have almost always been defined in male terms (Abbott \& Love, 1972). However, society has granted an assertive and rebellious girl a period of immunity before yielding to the endless restrictions and conditions of the female sex-role. This period, known as the "tomboy phase" was not one of imitating boys but one of experiencing a fuller range of activities. Evidence suggests that when a girl continues to participate in the "tomboy phase" past 
puberty and who finds success in these activities, her success forms a core part of her sex-role identity as well as a preference for that role (Bardwick, 1971 cited in Harris, 1980).

The literature has suggested that lesbian women more of ten than heterosexual women preferred boys' games, were regarded as "tomboys" and excelled in athletics. Data from a longitudinal study by psychologists in New York City revealed that of 225 lesbians questioned, $78 \%$ regarded themselves as tomboys in childhood; and out of 233 heterosexual women, $42 \%$ regarded themselves also as tomboys in childhood (Abbott \& Love, 1972). A study conducted by Gundlach \& Riess (1968) and cited in Brooks (1981) reported that three fourths of the lesbians sampled were "tomboys" as were nearly half of the comparison heterosexual women. Brooks (1981) also found that over three fourths of the respondents in her study reported participation in or preference for boys' activities as children. These findings suggest that girls who become lesbians as adults chose boys' activities more often than girls who became heterosexuals as adults. Also, it suggests that a preference for boys' activities in childhood is not because of imitation but of interest and increases along a continuum of adult female sociosexual orientations from heterosexual to bisexual to lesbian (Brooks, 1981). Abbot \& Love (1972) noted that some lesbian women found a similarity between intellectual or athletic achievement and the subsequent breaking of the heterosexual norm. These women realized that they had sought freedom and independence in many ways, and that most of these ways were considered masculine in our culture. Hence, according to Brooks (1981), the constraints imposed by the culturally assigned female sex-role are 
a salient factor in the lack of impetus toward heterosexual relationships and would account for the fact that lesbians simply do better in sports because the behavioral demands of competitive sports reinforce the personality characteristics that it takes to be an athlete and a Tesbian--independence, self-sufficiency, competitiveness, and ambition.

When answering the question "Do sports create lesbians?" the literature suggests that participation in sports doesn't necessarily create lesbians, but for those with lesbian tendencies it provides an atmosphere for that sexual behavior to occur especially at the college level (Lubenow et. al., 1982). College students today are confronted with the question of sexuality as never before. Whether exploring the unknown, admitting the obvious or choosing heterosexuality as the majority still do, a growing number of students are living together as homosexuals (Lubenow et al., 1982). Abbott \& Love (1972) have suggested that the college years are the time when a woman begins to define herself and explore the possibilities of adult life as well as the years when she may have had her first lesbian relationship. Saghir \& Robins (1973) noted that their subjects' potential partners were found at college and in the context of an athletic event. Gordon (1980) reported similar results: $15 \%$ of her population found partners while playing amateur team sports and $11 \%$ found partners while at college.

For some women, homosexual relations are just an experimental phase; shifts in sexual preference do indeed occur within an individual's lifetime (Freedman, 1971). Many of the homosexual experiences have emerged from the situational opportunities that college has provided. Sports at the collegiate level today provide a viable 
"situational opportunity" for a homosexual experience to occur; whether it be male athletes or female athletes. Women who play at the collegiate level are highly skilled and highly motivated athletes. Hicks (1979) has suggested that a young woman with gay tendencies who likes sports but is short of top-level-talent, and who lacks the motivation to acquire championship skills, or is deficient in the kind of independence and fortitude required to resist the stereotypical "feminine" sex-rnle, will probably complete her cultural assignment of wife and mother and not become a lesbian athlete. Subsequently, those lesbians on campus and/or athletic teams who were not homosexuals when they came to college may not be after they leave the "situational opportunity" (i.e. college and/or athletic team). Thus, this phenomenon has brought credence to Freedman's (1971) suggestion that sexual orientation is multidetermined and is created by the conjunction of past experiences and present circumstances.

The prevailing attitude toward homosexuals in the United States and many other countries is revulsion and hostility (Weinberg, 1973). Tripp (1975) mentioned that just because sexual variations are tolerated and talked about more freely than they were before does not mean they are better understood. Research in the area of homosexuality has indicated that the majority of Americans still have negative and disapproving images of homosexuals (Freedman, 1971; Guthrie, 1982; Laner \& Laner, 1980; Millham et. al., 1976; Nyberg \& Alston, 1977; \& San Miguel \& Millham, 1976).

Apparently there has been great controversy regarding the extent to which attitudes toward homosexuality can be changed (Guthrie, 1982). 
According to Nyberg \& Alston (1977) the holding of favorable/unfavorable attitudes toward homosexuality "is not a generational matter dependent upon the gradual aging of a more 'enlightened' generation," but rather incorporating a more liberal attitude which seems to be a function of one's social environment. Guthrie (1982) reported that approximately $36 \%$ of her subjects expressed negative feelings and deduced the following general reasons:

1. Religious practice and/or training (95\%)

2. Direct exposure to lesbians (5\%)

In contrast, approximately $33 \%$ of her subjects stated that their feelings toward lesbianism had become more positive for the following reasons:

1. Increased exposure to lesbians (e.g. family, friends, work associates) (45\%)

2. Increased knowledge/understanding of lesbianism (e.g. media, education) (40\%)

3. Development of a feminist consciousness (10\%)

4. Development of a humanitarian attitude (5\%)

However, these figures only constitute $69 \%$ of her population and no reference was made to the remaining $31 \%$ of the population that did not respond. These findings do provide support for Morin \& Garfinkle's (1978) claim that most of the fear surrounding homosexuality can be attributed to misinformation and lack of direct exposure to lesbians and gay men. Therefore, the literature suggests that major modifications need to be made in both the curricular structure of educational systems and in the attitudes of those directing the educational process. Open, 
honest interaction with lesbians and gay men is vital in promoting changes necessary for reducing and/or eliminating homophobia in one's social environment (Beck, 1980; Guthrie, 1982; Laner \& Laner, 1980; Towne, 1979; \& Weinberg, 1973).

\section{SUMMARY}

In reviewing the literature related to homophobia, pertaining specifically to lesbians, Guthrie's (1982) study was found to be the sole investigation using female athletes as a studied population.

The literature also describes the prevalence of lesbianism in this country as an estimation due to the lack of investigations and systematic studies. It is evident that the prevalent attitude toward homosexuals in the United States is still revulsion and hostility despite the toleration and sexual revolution that society has experienced. The research indicates that the majority of Americans still have negative and disapproving images of homosexuals. 


\section{METHODOLOGY}

The methodology followed in this study is presented in the following sections: Sample Description, Instrumentation, Procedures, and Analysis of the Data.

\section{SAMPLE DESCRIPTION}

The study sample consisted of two groups: Female team sport college athletes and female team sport recreational players. There were 32 female team sport college athletes representing four Utah university/college campuses and one Oregon university/college campus. A number of teams on the collegiate level did not want to participate in the study. Sixteen teams (i.e., volleyball, basketball, softball) at six collegiate institutions were contacted and only five of these teams agreed to participate in the study. This statistic is highly significant to the study because it reveals the current attitudes of many coaches and athletic departments regarding the issue of homosexuality that of avoidance and fear.

It is understandable that during the economic conditions of the times and the fear of budget cuts that institutions are cautious about the types of studies in which they allow their departments to participate. However, in order to alleviate or dispel the lesbian stereotype that the majority of female athletes experience, athletic teams need to be willing to participate in research. Their noncompliance could add further impetus to the negative feelings in the 
issue because the public might assume the lack of participation is due to the prevalence of lesbianism on their teams.

There were 35 female team sport recreational players representing four Utah recreational teams and two Oregon recreational teams. Twenty seven of the 35 recreational team sport players were former college team sport athletes.

Data were collected during the months of March through June, 1983. A11 subjects participating were 18 years of age or older and were volunteers. The subjects' ages ranged from $18-35$, the mean age being 23.5 . Descriptive data for college athletes and recreational players by age are presented in Table 1.

\section{TABLE I}

A COMPARISON OF FEMALE TEAM SPORT COLLEVE ATHLETES AND FEMALE TEAM SPORT RECREATIONAL PLAYERS BY AGE

\begin{tabular}{cccc}
\hline & College Athlete & & \\
\hline & $\begin{array}{c}\text { Recreational Player } \\
n=35\end{array}$ & $\begin{array}{r}\text { Total } \\
n=67\end{array}$ \\
\hline age & 8 & 0 & 8 \\
$15-19$ & 24 & 19 & 43 \\
$20-24$ & 0 & 7 & 7 \\
$25-29$ & 0 & 6 & 6 \\
$30-34$ & 0 & 3 & 3 \\
$35-39$ & 19.8 & 26.0 & \\
mean age & & 23.5 \\
\hline
\end{tabular}

The survey was anonymous and optional, and those who volunteered were asked to mark a form with an " $X "$ to ensure they understood the nature and purpose of the study. The consent form is located in Appendix A. 


\section{INSTRUMENTATION}

The instruments used in this study were: 1) Index of Attitudes Toward Lesbians (designed by Guthrie, 1982), 2) Demographic/Social Variable Data.

Index of Attitudes Toward Lesbians (IAL)

The IAL is a 26 -item summated category partition scale developed by Guthrie (1982). It is a modified version of the original instrument developed by Hudson \& Ricketts (1980) and measures homophobia. The IAL consists of statements to be rated on a 5-point Likert-type scale of Strongly Agree to Strongly Disagree. Possible scores range from zero to 100 with higher scores indicating more negative emotional response to lesbianism (i.e., homophobia). Half of the items on the IAL represent positive emotional responses to contact with lesbians while the other half represent negative responses. Equal numbers of positive and negative statements are used to control for response set biases. In addition, 25 filler-items are included in the text of the IAL in an effort to disguise the purpose of the instrument. Scores are categorized as follows: subjects who score zero to 25 are regarded as "high grade non-homophobic"; those who score from 26-50 are "low grade non-homophobic"; individuals with scores of 51-75 are classified as "low grade homophobic"; while those with a score of 76 or above represent "high grade homophobic". To score the IAL, it is first necessary to reverse score all of the negatively worded items (i.e., a score of $1=5$, 
$2=4,3=3,4=2,5=1)$. After the appropriate items have been reversescored, the total IAL score is computed as follows:

$$
s=\{x-30
$$

where $x$ is a single item score. In addition, if a respondent has left blank or inaccurately completed any item, the total IAL score may be derived with the following formula:

$$
S=(\{X-N)(100) /\{(N)(4)\}
$$

where $X$ is a single item score and $N$ is the number of items that were properly completed. Any item which is left blank or scored outside the range from one to five is scored as zero and regarded as having been omitted.

The items on the IAL were derived from two sources. The majority were similar or identical to those on the IHP (Hudson \& Rifketts, 1980). The remainder were created by Guthrie (1982) based on a review of the literature pertaining to women in sport and physical education. All statements were reworded so that they applied to various situations involving lesbians only, rather than homosexuals in general.

Guthrie (1982) found the IAL to be both a highly reliable and valid instrument for measuring homophobia. The reliability and validity of the instrument were examined by correlating the scores obtained on the IAL with those on the IHP; the correlation was .92. The content validity of the IAL was further obtained by computing intercorrelations for each of the 26 items. All correlations were positively related (p<.05). Factorial validation was addressed with an item-analysis. The 26-item total correlations showed that each item correlated positively with the total IAL score within a range of .60 to .85 . The mean 
item-total correlation for all cases was .65. All of the item-total correlations were statistically significant at $(\underline{p}<.01)$. As no other instrument had been developed specifically for female athletes to examine homophobia pertaining to lesbians, the credibility of the IAL seemed to justify its use in this study. The Index of Attitudes Toward Lesbians is located in Appendix B.

Demographic/Social Variables

The researcher used the same demographic/social variable instrument as Guthrie (1982) but with two modifications to accommodate the responses of the Female Team Sport Recreational Player. "Occupation" was included for those recreational players who were not in college, and a response in item number 1 (i.e., (e) nonappiicable) was added.

The social variables specifically concentrated upon in this study were items number 23 (i.e., sexual preference/intimate); number 24 (i.e., first learn sexual intimacy among women); number 25 (i.e., feelings changed); and number 26 (i.e., reason(s) for change in feelings). The Demographic/Social Variable instrument is located in Appendix C.

\section{PROCEDURE}

The researcher requested approval to administer the survey instruments from the coaches of the collegiate and recreational teams. After permission was granted, a visit was made to each team and a brief verbal explanation of the study was given, stressing confidentiality and optional participation. To insure total anonymity, no names were placed 
on the respondents' answer sheets and subjects were informed of their right to refuse to participate at any time before, during, or after the survey session. Those subjects volunteering were asked to mark a consent form with the understanding of the nature and purpose of the study and have a witness mark an " $X$ " acknowledging that the subject read and understood the form.

After the consent form was marked, those subjects who volunteered were asked to complete the survey form consisting of the IAL and the Demographical/Social Data, in that order (cf. Appendix B, Appendix C). After completion they were given to the researcher and put in a file. Each instrument contained a set of written directions for appropriate responding.

\section{ANALYSIS OF THE DATA}

Chi-Square Analysis were used to assess the differences in degree of homophobia and lesbian sexual preference behavior between the female team sport college athletes and the female team sport recreational players.

Also the relationship between the social variable item number 25 (i.e., change in feelings) and level of homophobia between the female team sport college athletes and the female team sport recreational players was evaluated employing Chi-Square Analyses. 
The main investigation of this study was to determine if a difference existed in the degree of homophobia, expressed lesbian sexual preference behavior, and attitudes towards lesbianism between two groups: the female team sport college athlete and the female team sport recreational player as measured by Guthrie's (1982) Index of Attitudes Toward Lesbians (IAL) and Demographic/Social Variables Instrument. This is based on the assumption that a difference does exist in the length of time each group spends conditioning, practicing, and playing together.

An analysis of data from responses to the IAL and Demographic/ Social Variable Instrument is presented in this chapter. Data were obtained from 32 female team sport college athletes and 35 female team sports recreational players.

\section{Informal Hypotheses}

Female team sport college athletes will

be less homophobic than female team

sport recreational players.

It was hypothesized that female team sport college athletes would be less homophobic than female team sport recreational players. Raw scores obtained on the IAL were converted to a total IAL score after the appropriate items had been reverse-scored. Scores were categorized as follows: subjects who scored from zero to 25 are regarded as "high grade non-homophobic"; those who scored from 26 to 50 are "low grade non-homophobic"; where individuals with scores of 51 to 75 were classified as "low grade homophobic"; while those with a score of 76 or above represent "high grade homophobic". 
There was no significant difference between the two groups in terms of their level of homophobia $\left(x^{2}(3)=3.02\right.$, n.s.). These results are summarized in Table 2.

\section{TABLE II}

\section{CATEGORICAL SCORES OF HOMOPHOBIA BETWEEN FEMALE \\ TEAM SPORT COLLEGE ATHLETES AND FEMALE TEAM SPORT RECREATIONAL PLAYERS}

\begin{tabular}{|c|c|c|c|c|c|c|}
\hline $\begin{array}{c}\text { Categorical Score } \\
\text { Homophobia }\end{array}$ & $\begin{array}{l}{ }^{\star} C . A . \\
n=32\end{array}$ & $\begin{array}{c}x=54.25 \\
\%\end{array}$ & $\begin{array}{l}\star \mathrm{R} . P . \\
n=35\end{array}$ & $\begin{array}{c}x=50.43 \\
\%\end{array}$ & $\begin{array}{c}\text { Total } x=52.34 \\
n=67\end{array}$ & $\%$ \\
\hline $\begin{array}{l}\text { High Grade } \\
\text { Non-Homophobic } \\
\text { (i.e., score 0-25) }\end{array}$ & 3 & 9.3 & 7 & 20.0 & 10 & 15.0 \\
\hline $\begin{array}{l}\text { Low Grade } \\
\text { Non-Homophobic } \\
\text { (i.e., score 26-50) }\end{array}$ & 11 & 34.4 & 7 & 20.0 & 18 & 27.0 \\
\hline $\begin{array}{l}\text { Low Grade Homophobic } \\
\text { (i.e., score } 51-75)\end{array}$ & 12 & 37.5 & 16 & 45.7 & 28 & 42.0 \\
\hline $\begin{array}{l}\text { High Grade Homophobic } \\
\text { (i.e., score } 76+\text { ) }\end{array}$ & 6 & 18.8 & 5 & 14.3 & 11 & 16.0 \\
\hline
\end{tabular}

*C.A. denotes college athlete

$* R$.P. denotes recreational player

Female Team Sport College Athletes

Wi17 Express Greater Lesbian

Sexuat Preference Than Female

Team Sport Recreational Players

It was hypothesized that female team sport college athletes would express greater lesbian sexual preference behavior than female team sport recreational players. Data were analyzed from the responses to $\underline{\text { Item }} 23$ on Demographic/Social Variable. The question, "With whom are you sexually intimate?" produced the following responses from the female sport college athletes and female team sport recreational players and are summarized in Table 3. 
TABLE III

SEXUAL PREFERENCE BEHAVIOR OF FEMALE TEAM SPORT COLLEGE ATHLETES AND FEMALE TEAM SPORT RECREATIONAL PLAYERS

\begin{tabular}{|c|c|c|c|c|c|c|}
\hline Sexua11y Intimate & $\begin{array}{l}{ }^{\star} C . A . \\
n=32\end{array}$ & $\%$ & $\begin{array}{l}{ }^{* R} . P \\
n=35\end{array}$ & $\%$ & $\begin{array}{l}\text { Total } \\
n=67\end{array}$ & $\%$ \\
\hline Only Opposite Sex & 13 & 40.6 & 18 & 51.4 & 31 & 46.0 \\
\hline $\begin{array}{l}\text { Usually Opposite } \\
\text { Sex/0ccasionally } \\
\text { Same }\end{array}$ & 2 & 6.3 & 0 & 0.0 & 2 & 3.0 \\
\hline $\begin{array}{l}\text { Usually Same Sex/ } \\
\text { Occasionally Opposit }\end{array}$ & $e^{3}$ & 9.4 & 3 & 8.6 & 6 & 9.0 \\
\hline Only Same Sex & 3 & 9.4 & 7 & 20.0 & 10 & 15.0 \\
\hline No One & 11 & 34.4 & 7 & 20.0 & 18 & 27.0 \\
\hline
\end{tabular}

*C.A. denotes college athlete

*R.P. denotes recreational player

There was no significant difference between the two groups in terms of their lesbian sexual preference behavior $\left(x^{2}(4)=5.17\right.$, n.s. $)$.

Female Team Sport College Athletes

Will Possess More Positive Attitudes

Toward Lesbianism Than FemaTe

Team Sport Recreational Players

It was hypothesized that female team sport college athletes would possess more positive attitudes toward lesbianism than female team sport recreational players. Data were analyzed from the responses to Item $\underline{25}$ on Demographic/Social Variable. The question, "To what extent have your feelings toward lesbianism changed over the past five years?" produced the following responses from the female team sport college athletes and female team sport recreational players and are summarized in Table 4. 


\section{COMPARISON OF ATTITUDES TOWARD LESBIANISM BETWEEN \\ FEMALE TEAM SPORT COLLEGE ATHLETES AND FEMALE \\ TEAM SPORT RECREATIONAL PLAYERS}

\begin{tabular}{lccrrrr}
\hline Attitude & $\begin{array}{c}{ }^{* C} \text {. A. } \\
n=32\end{array}$ & $\%$ & $\begin{array}{r}{ }^{*} \mathrm{R} . \mathrm{P} . \\
n=35\end{array}$ & $\%$ & $\begin{array}{r}\text { Total } \\
n=67\end{array}$ & $\%$ \\
\hline More Positive & 8 & 25.0 & 8 & 22.9 & 16 & 24.0 \\
Somewhat Positive & 9 & 28.1 & 12 & 34.3 & 21 & 31.0 \\
No Change & 6 & 18.8 & 9 & 25.7 & 15 & 22.0 \\
Somewhat Negative & 2 & 6.3 & 4 & 11.4 & 6 & 10.0 \\
More Negative & 7 & 21.9 & 2 & 5.7 & 9 & 13.0 \\
\hline
\end{tabular}

*C.A. denotes college athlete

$\star_{R}$. P. denotes recreational player

There was no significant difference between the two groups in terms of their positive attitudes toward lesbianism $\left(X^{2}(4)=4.35\right)$.

Responses to Item $\underline{26}$

Responses to the question, "If there has been a change in your feelings toward lesbianism in the past five years what is the reason(s) for this change?" were analyzed. Two of the test items in the Demographic and Social Variables Instrument (Guthrie, 1982) were examined to determine possible variables in the change of attitudes toward lesbianism. For the female team sport college athletes and female team sport recreational players who reported their feelings had changed to be negative, the following reasons reported for the change in feelings were:

Female Team Sport College Athletes

1. Direct exposure to lesbians $19 \%$

2. Morally Wrong 
Female Team Sport Recreational Players

1. Direct exposure to lesbians $10 \%$

2. Morally wrong $4 \%$

For the female team sport college athletes and female team sport recreational players who reported their feelings had changed to be positive, the following reasons reported for the change in feelings were:

Female Team Sport College Athletes

1. Increased exposure to lesbians (e.g., friends, family, work/school associates).

2. Increased knowledge/understanding of lesbianism (e.g., media, education).

3. Development of a humanitarian attitude. $16 \%$

Female Team Sport Recreational Players

1. Increased exposure to lesbians (e.g., friends, family, work/school associates).

2. Increased knowledge/understanding of lesbianism (e.g., media, education). $26 \%$

3. Development of a humanitarian attitude. $23 \%$

Responses to Item 24

The open ended question, "How did you first learn about sexual intimacy among women?" produced the following responses from the female team sport college athletes and female team sport recreational players. These responses are summarized in Table 5. 


\section{TABLE $V$}

FIRST EXPOSURE OF SEXUAL INTIMACY BETWEEN WOMEN FROM FEMALE TEAM SPORT COLLEGE ATHLETES AND FEMALE TEAM SPORT RECREATIONAL PLAYERS

\begin{tabular}{|c|c|c|c|c|c|c|}
\hline Source & $\begin{array}{l}{ }^{\star C} . \bar{A} . \\
n=32\end{array}$ & $\%$ & $\begin{array}{l}\text { *R.P. } \\
n=35\end{array}$ & $\%$ & $\begin{array}{r}\text { Total } \\
n=67\end{array}$ & $\%$ \\
\hline $\begin{array}{l}\text { Books, magazines, } \\
\text { newspapers, movies }\end{array}$ & 6 & 18.7 & 8 & 22.9 & 14 & 20.9 \\
\hline Friends, peers & 15 & 46.9 & 6 & 17.1 & 21 & 31.3 \\
\hline $\begin{array}{l}\text { Courses (e.g., } \\
\text { sexuality, health) }\end{array}$ & 3 & 9.4 & 3 & 8.6 & 6 & 8.9 \\
\hline $\begin{array}{l}\text { Direct Exposure } \\
\quad \text { (e.g., sports' team) }\end{array}$ & 6 & 18.8 & 13 & 37.0 & 19 & 28.4 \\
\hline $\begin{array}{l}\text { Awareness of our } \\
\text { sexuality }\end{array}$ & 1 & 3.1 & 4 & 11.5 & 5 & 7.5 \\
\hline
\end{tabular}

These data were examined to determine whether or not the college athletes and recreational players had their first exposure of sexual intimacy between women on a sports' team.

It is interesting to note that a large percentage of both college athletes $(65.7 \%)$ and recreational players $(54.1 \%)$ reported their first exposure of sexual intimacy between women was either with friends and peers or on a sports' team.

\section{Summary of Major Results}

The major results of this study indicated that there was no significant difference in the degree of homophobia between the two groups (i.e., score of 51-75) with female team sport college athletes' 
accounting for $37.5 \%$ and female team sport recreational players $45.7 \%$.

Also, no significant difference existed between the two groups and their lesbian sexual preference behavior. However, it is interesting to note that $25.1 \%$ of the female team sport college athletes and $28.6 \%$ of the female team sport recreational players did express intimacy with the same sex occasionally or entirely.

No significant difference existed between the two groups concerning positive attitudes toward lesbianism. Fifty-three percent of the female team sport college athletes expressed "more" or "somewhat" positive attitudes toward lesbianism compared to $57 \%$ of the female team sport recreational players. Twenty-eight percent of the female team sport college athlete's expressed "more" or "somewhat" negative attitudes toward lesbianism compared to $17 \%$ of the female team sport recreational players.

Sexual intimacy among women was first learned by $46.9 \%$ of the female team sport college athletes through friends and peers; whereas $37 \%$ of female team sport recreational players became aware of intimacy among women through direct exposure with lesbians (e.g., sports team).

Nineteen percent of the female team sport college athletes and $12 \%$ of the female team sport recreational players had a change in feelings towards "more and/or negative" because of direct exposure to lesbians as well as $12 \%$ of the female team sport college athletes and $4 \%$ of the female team sport recreational players stating that lesbianism is morally wrong. Twenty-eight percent of the female team sport college athletes and $28 \%$ of the female team sport recreation players' attitudes had become more positive because of increased exposure to lesbians compared to $23 \%$ 
of the female team sport recreational players. Also mentioned was increased knowledge/understanding of lesbianism by the female team sport college athletes (6\%) and female team sport recreational players (26\%). 


\section{SUMMARY AND CONCLUSIONS}

The purpose of this study was to determine the degree of homophobia, expressed lesbian sexual preference behavior, and the expression of attitudes toward lesbianism between the female team sport college athlete and the female team sport recreational player. Research results have been discussed in relation to both the informal hypotheses and social variable items number $23,24,25,26$. proposed in Chapter 1.

\section{Informal Hypotheses}

It Was Predicted That The

Female Team Sport College

Athlete Would Be Less

Homophobic Than The

Female Team Sport

Recreational Player

The results of this investigation did not support the hypothesis in that the statistical findings indicated no significant difference in degree of homophobia between the female team sport college athlete and the female team sport recreational player ( $p<.01$ ) (cf. Table 2). However, $37.5 \%$ of the female team sport college athletes expressed "Low Grade Homophobia" (i.e., IAL Score of 51-75); whereas $45.7 \%$ of the female team sport recreational players expressed "Low Grade Homophobia".

It Was Predicted That The

Female Team Sport College

Athlete Would Express Greater

Lesbian Sexual Preference

Behavior Than The Female Team Sport Recreational Player

The literature has demonstrated that women who engage in competitive sports are consistently threatened with the loss of both their 
femininity and heterosexuality. Because female team sport college athletes are committed to an extensive conditioning, practicing, traveling program it was predicted that these women would express greater lesbian sexual preference behavior than the female team sport recreational player.

This hypothesis was not supported by the data. There was no significant difference between the two groups concerning lesbian sexual preference behavior ( $\underline{0}<.01$ ( $c f$. Table 3 ). However, $25.1 \%$ of the female team sport college athletes expressed lesbian sexual preference behavior, while $28.6 \%$ of the female team sport recreational players stated such. An interesting statistic was that $34.4 \%$ of the female team sport college athletes were not sexually intimate with anyone as compared to $20 \%$ of the female team sport recreational players. It is possible that the nature and sensitivity of this study led many athletes and players to select this response as a safety measure despite the knowledge of complete anonymity and confidentiality stressed by the researcher.

It Was Hypothesized That Female

Team Sport College Athletes

WouTd Possess More Positive

Attitudes Toward Lesbianism

Than Female Team Sport

Recreational Players

This hypothesis was not verified statistically. The data showed no significant difference existed between the female team sport college athletes and the female team sport recreational players $(p<.01)$ (cf. Table 4). Both groups expressed a high percentage of "somewhat" or "more" positive attitudes towards lesbianism. Moreover, the question, "Why has there been a change in your feelings toward lesbianism over the 
past five years?" produced the following general reasons for feelings becoming more positive from approximately $55 \%$ of the sample:

1. Increased exposure to lesbians (e.g., friends, family, work/school associates)

2. Increased knowledge/understanding of lesbianism (e.g., media, education) $(6 \%)$

3. Development of a humanitarian attitude (27\%)

These findings provide substantiation for Morin \& Garfinkle's (1978) claim that most fear surrounding homosexuality can be attributed to ignorance about or lack of direct exposure to lesbians and gay men. Responses to the question, "How did you first learn about sexual intimacy among women?" indicated that the primary sources of knowledge regarding lesbianism was direct exposure to lesbians (30\%). Other significant sources of initial exposure were family, friends, and peers $(27 \%)$; books, magazines, newspapers, and movies (21\%). It appears then that increased awareness through interaction with lesbians and gay men, plus education (i.e., media) may reduce and/or eliminate homophobia.

\section{Conclusions}

The following conclusions were drawn from this research investigation:

1. Of the 16 coaches at universities and colleges who were asked to participate in this survey, only 5 volunteered. This low rate of participation in this study implies a high percentage (67\%) of coaches unwilling to associate with research in this area. 
of the 6 recreational teams who were asked to participate in this survey, all 6 volunteered. This high rate of participation implies that coaches of recreational teams are less inhibited to associate with research in this area.

This noncompliance factor gives reason to the conservative nature of the data in this study.

2. A low degree of homophobia was prevalent within both the sample of female team sport college athletes and female team sport recreational players, although there was no significant difference in the degree of homophobia between the two groups.

3. Twenty-five point one percent of the female team sport recreational players expressed lesbian sexual preference behavior, although there was no significant difference of expressed lesbian sexual preference behavior between the two groups.

4. Fifty-five percent of the respondents in both groups reported an increase in positive attitudes towards lesbianism, however there was no significant difference concerning the increase of positive attitudes towards lesbianism over the last five years.

5. Increased exposure and interaction with lesbians as well as increased knowledge and understanding of lesbianism appeared to be major aids in reducing and/or eliminating homophobia.

\section{Final Observations}

Given the assumption that a sample had been drawn from two distinct groups, the researcher discovered that in reality there was only one group. Of the 35 female team sport recreational players that participated in the study, 27 were former team sport college athletes. Post hoc analyses of 
data were performed combining the group of college athletes and the recreational players who were former college athletes $(N=27)$. This group, then, was divided into age groups (15-19 yr.; 20-24 yr.; 25-29 yr.; 30-34 yr.; 35-39 yr.) to determine whether age was a factor in degree of homophobia, the expression of lesbian sexual preference behavior, and the expression of positive attitudes toward lesbianism.

Of the 27 female team sport recreational players who were former female team sport college athletes, 16 (59\%) were between the ages of 20-24. In comparison to the 32 present female team sport college athletes who participated in the study, 24 (94\%) were between the ages of $20-24$. From this observation, many similarities of this segment (i.e., age 20-24) are noted and the following characteristics were discovered:

1. Nine (33\%) of the 16 former female team sport college athlete/female team sport recreational players and $12(50 \%)$ of the 24 present female team sport college athletes between the ages of 20-24 years expressed non-homophobia (i.e., an IAL score of 50 and below).

2. Seven (25.9\%) of the 16 former female team sport college athlete/female team sport recreational players and $6(25 \%)$ of the 14 present female team sport college athletes between the ages of 20-24 years expressed lesbian sexual preference behavior.

3. Twelve $(44.4 \%)$ of the 16 former female team sport college athlete/female team sport recreational players and $14(43.8 \%)$ of the 24 present female team sport college athletes between the ages of 20-24 years expressed "more" or "somewhat" positive attitudes toward lesbianism.

The similarities found within this specific age group (i.e., 20-24), could explain the statistical non-significance of the data that was 
reported in the study and confirm the likelihood that, indeed, there was only one group. The post hoc analyses of the data also reveals that this particular age group (i.e., 20-24) encompasses a great proportion of the college age women who do participate in athletics and that the exposure, involvement, and attitudes concerning lesbianism are noticeably prevalent in the college athletic environment. 
REFERENCES 


\section{REFERENCES}

Abbott, S. \& Love, B. Sappho was a right-on woman. New York: Stein \& Day, 1972.

Adelman, M. R. A comparison of professionally employed

lesbian/heterosexual women on the MMPI. Archives of Sexual

Behavior, May 1977, $\underline{3}, 199$.

Axthe 1m, P. The case of Billie Jean King. Newsweek, May 18, 1981, 97.

Beach, B. H. A disputed love match. Time, May 11, 1981, 117, 25.

Beck, B. A. No more masks! A feminist perspective on issues and directions in professional preparation. Proceedings of the National Association for Physical Education in Higher Education (NAPEHE), $1980,2,126-135$.

Berry, D. F., \& Marks, P. Anti-homosexual prejudice as a function of attitudes toward sexuality. Proceedings 77th Annual Convention, APA, n.p., 1969.

Bianchi, E. C. The super-bowl culture of male violence. In Sabo, D. R. \& R. Runfola (EdS.), Jock: Sports \& Male Identity. Englewood Cliffs, New Jersey: Prentice-Ha17, Inc., 1980.

Birre11, S. Achievement related motives and the woman athlete, Chapter 8 in Women and sport: From myth to reality, C. A. Oglesby, ed. Philadelphia: Lea \& Febiger, 1978.

Boslooper, R., \& Hayes, M. Cinderella was a winner. In A. Yiennakis et. al. (EdS.), Sport Sociology-Contemporary Themes. Dubuque, Iowa: Kenda11/Hunt Publishing Co., 1976.

Brooks, V. R. Minority stress and lesbian women. Lexington, MA: Lexington Books, 1981.

Brown, M., \& Amoroso, D. M. Attitudes toward homosexuality among West Indian male and femlae college students. Journal of Social Psychology, 1975, 97, 163-168.

Bullough, V., \& Bullough, B. Lesbianism in the 1920's and 1930's: A newfound study. Signs, 1977, 2, 895-904.

Chafetz, J. S. Masculine/Feminine/or Human? Itasca, Illinois: F. E. Peacock PubTishers Inc., 1974.

Churchill, W. Homosexual behavior among males. New York: Hawthorne Books, 1976.

Clark, D. Loving someone gay. New York: The New American Library, 1977. 
Cotton, W. L. Social and sexual relationships of lesbians. The Journal of Sex Research, May 1975, 2, 139-148.

Deaux, K. The behavior of men and women. Monterey, CA: Brooks/Cole Publishing Co., $197 \overline{6}$.

DelRey, P. Apologetics and androgyny: The past and the future. Frontiers: A Journal of Women's Studies, 1978, $\underline{3}(1), 8-10$.

DelRey, P. The apologetic and women in sport, Chapter 6 in Women and sport: From myth to reality, C. A. Oglesby, ed. Philadelphia: Lea \& Febiger, 1978 .

Duquin, M. E. The androgynous advantage, Chapter 5 in Women and sport: From myth to reality, C.A. Oglesby, ed. Philadelphia: Lea \& Febiger, 1978 .

Elkins, H. Time for a change: Women's athletics and the women's movement. Frontiers: A Journal of Women's Studies, 1978, $\underline{3}(1), 22-25$.

Ellis, A. Homosexuality: Its causes and cure. New York: Stuart Publishing Co., 1965.

Ettorre, E. M. Lesbians, women, and society. London: Routledge \& Kegan Paul Ltd., 1980.

Fairchild, B., \& Hayward, N. Now that you know. New York: Harcourt Brace, 1977.

Freedman, M. Homosexuality and psychological functioning. Belmont, CA: Brooks/CoTe Publishing Co., 1971.

Gagnon, J. H., \& Simon, W. Femininity in the lesbian community. Social Problems, Fall, 1967, 2, 212-221.

Gerber, E. W., The american woman in sport. Reading, MA: Add ison-Wesley, 1974.

Gordon, K. Norms of thriving lesbian relationships. Unpublished master's thesis, University of Oregon Health Sciences Center, 1980.

Greendorfer, S. L. Socialization into sport, Chapter 7 in Women and sport: From myth to reality, C.A. Oglesby, ed. Philadelphia: Lea \& Febiger, 1978 .

Guthrie, S. R. Homophobia: Its impact on women in sport and physical education. Unpublished master's thesis, California State University, Long Beach, 1982.

Hart, M. Sport: Women sit in the back of the bus. In Sabo, D. F. \& R. Runfola (Eds.), Jock: Sports and male identity. Englewood Cliffs, New Jersey: Prentice-Hal1, Inc., 1980. 
Hart, M. Stigma or prestige: The all-american choice. In A. Yiannakis et. al. (Eds.), Sport Sociology-Contemporary Themes. Dubuque,

Iowa: Kendal/Hunt PubTishing Co., 1976.

Harris, D. V. Female sport today: Psychological considerations. International Journal of Sports Psychology, 1979, 10, 168-172.

Harris, D. V. Femininity and athleticism: Conflict or consonance?

In Sabo, D. F. \& R. Runfola (Eds.), Jock: Sports and male identity. Englewood Cliffs, New Jersey: Prentice-Hall, Inc., 1980.

Hicks, B. Lesbian athletes. Christopher Street, 1979, 45, 42-50.

Hoch, P. School for sexism. In Sabo, D. F. \& R. Runfola (Eds), Jock: Sports and male identity. Englewood Cliffs, New.Jersey:

Prentice-Hall Inc., 1980.

Holmen, M. G., and Parkhouse, B. L. Trends in the selection of coaches for female athletes: A demographic inquiry. Research Quarterly for Exercise \& Sport, 1982, 르, 9-18.

Hood, R. W. Dogmatism and opinions about mental illness. Psychological Reports, 1973, 32, 1283-1290.

Hudson, W. W., \& Ricketts, W. A. A strategy for the measurement of homophobia. Journal of Homosexuality, $1980, \underline{5}, 357-372$.

Hyde, J. S. Understanding human sexuality. New York: McGraw-Hill Inc., 1982 .

Johnston, J. Lesbian nation-The feminist solution. New York: Simon \& Schuster, 1973.

Kennard, J. A. The history of physical education. Signs, 1977, 2 , 835-842.

Klaich, D. Woman + woman-Attitudes toward lesbianism. New York: Simon \& Schuster, $1 \overline{9} 7 \overline{4}$.

Kopya, D., \& Young, P. D. Homosexuality and machismo sport: A gay jock speaks out. In Sabo, D. F. \& R. Runfola (Eds.), Jock: Sports and male identity. Englewood Cliffs, New Jersey: Prentice-Ha11 Inc., 1980 .

Kort, $M$. Is she or isn't she? Women athletes and their gender identity. Chrysalis, Fall 1979, 76-79.

Laner, M., Y Laner, R. Sexual preference or personal style? Why lesbians are disiliked. Journal of Homosexuality, 1980, $\underline{5}, 339-356$.

Lehne, G. K. Homophobia among men. In David, D. S., \& Grannon, R. (Eds.), The forty-nine percent majority. Phillipines:

Addison-Wes ley, 1976. 
Levitt, E. E., \& Klassen, A. D. Public attitudes toward homosexuality: Part of the 1970 national survey by Institute for Sex Research. Journal of Homosexuality, 1974, 1, 29-43.

Lubenow, G. C., Abramson, P., \& King, P. Gays and lesbians on campus. Newsweek, Apri1 5, 1982, 97, 75-77.

Lumby, M. E. Homophobia: The quest for a valid scale. Journal of Homosexuality, 1976, 2, 39-46.

Martin, D., \& Lyon, P. Lesbian/woman, San Frnacisco, CA: Glide Publications, 1972 .

Mathes, S. Body image and sex stereotyping, Chapter 3 in Women and sport: From myth to reality, C. A. Oglesby, Ed. Philadelphia: Lea \& Febiger, $197 \overline{8}$.

Metheny, E. Symbolic forms of movement: The feminine image in sports, In $E$. Metheny (Ed.), Connotations of movement in sport and dance. Dubuque, Iowa: Wm. C. Brown, 1965.

Miller, D. M. Coaching the female athlete. Philadelphia: Lea \& Febiger, 1974 .

Millham, J., San Miguel, C. C., \& Kellogg, R. A factor-analytic conceptualization of attitudes toward male and female homosexuals. Journal of Homosexuality, 1976, 2, 3-10.

Money, J., \& Tucker, P. Sexual signatures-On being a man or a women. Boston: Little, Brown \& Co., 1975.

Morin, S. F. Educational programs as a means of changing attitudes toward gay people. Homosexual Counseling Journal, 1974, 1, 160-165.

Morin, S. F., \& Garfinkle, E. M. Male homophobia. Journal of Social Issues, $1978, \underline{34}(1), 29-47$.

Morin, S. F., \& VanSharik, B. Don't ask David Rubin: Changing attitudes toward homosexuality through reading. Unpublished manuscript, California State College, San Bernadino, 1975.

Neal, P. Coaching methods for women. Reading, MA: Addison-Wesley, 1978 .

Neal, P. Sport and identity. Philadelphia: Dorrance \& Company, 1972.

Nyberg, K. L., \& Alston, J. P. Analysis of public attitudes toward homosexual behavior. Journal of Homosexuality, 1976-1977, 2 , 99-107.

0akley, A. Sex, gender, and society. London: Temple Smith, 1972. 
Oglesby, C. A. The masculinity/femininity game: Called on account of.... Chapter 4 in Women and sport: From myth to reality, C. A. Oglesby, Ed. Philadelphia: Lea \& Febiger, 1978.

Poole, K. A. A sociological approach to the etiology of female homosexuality. Unpublished doctoral dissertation, University of Southern California, 1970.

Rich, A. Compulsory heterosexuality and lesbian existence. Signs, Summer $1980, \underline{4}, 631-660$.

Roberts, S. Bad form Billie Jean. Newsweek, May 25, 1981, 97, 19.

Sage, G. H., \& Loudermilk, S. The female athletes and role conflict. Research Quarter ly, March 1979, 50, 88-96.

Saghir, M. T., \& Robins, E. Male and female homosexualtiy: A comprehensive investigation. Baltimore, MD: The Williams \& Wilkins Co., 1973.

San Miguel, C. L., \& Millham, J. The role of cognitive and situational variables in aggression toward homosexuals. Journal of Homosexuality, 1976, 2, 12.

Schafer, S. Sexual and social problems among lesbians. The Journal of Sex Research, February 1976, 1, 50-59.

Schafer, S. Sociosexual behavior in male/female homosexuals: A study in sex differences. Archives of Sexual Behavior, September 1977, $\underline{5}, 360$.

Simpson, R. From the closet to the courts-The lesbian transition. New York: The Viking Press, 1976.

Snyder, E. E., \& Spreitzer, E. Social aspects of sport. Englewood Cliffs, New Jersey: Prentice-Ha71 Inc., 1978.

Spears, B. Prologue: The myth, Chapter 1 in Women and sport: From myth to reality, C. A. Oglesby, Ed. Philadelphia: Lea \& Febiger, 1978.

Storms, M. D., Stivers, M. L., Lambers, S. M., \& Hill, C. A. Sexual scripts for women. Sex Roles, July 1981, $\underline{7}, 699-707$.

Towne, W. S. Beliefs, attitudes, intentions, and behavior: The gay rights issue. Unpublished doctoral dissertation, University of Hawaii, December, 1979.

Tripp, C. A. The homosexual matrix. New York: McGraw Hill Book Co., 1975. 
Uguccioni, S. M., \& Ballantyne, R. H. Comparison of attitudes and sexroles for female athletic participants and nonparticipants.

International Journal of Sports Psychology, 1980, 11, 42-48.

Weber, J. Lesbian networks. Christopher Street, April 1979, $\underline{3}, 51-54$. Weinberg, G. Society and the healthy homosexual. New York: Anchor Press, 1973.

Wolff, C. Love between women. London: Gerald Duckworth \& Co., 1973.

Wughalter, E. Ruffles and flounces: The apologetic in women's sports. Frontiers: A Journal of Women's Studies, 1978, $\underline{3}(1), 11-13$.

Zoble, J. E. Femininity and achievement in sports. In A. Yiannakis et. al. (Eds.), Sport Sociology-Contemporary Themes. Dubuque, Iowa: Kenda11/Hunt Pub7ishing Co., 1976. 
APPENDICES 
APPENDIX A

INFORMED CONSENT LETTER

I hereby agree to serve as a subject in the research project on Lesbianism in Sport: From the perspective of the Female Team sport College Athlete and Female Team sport Recreational Player conducted by Tracy Jaynes.

I understand that the study involves participating in two questionnaires that should take $30-45$ minutes to complete

It has been explained to me that the purpose of the study is to learn the relationship between participation in sports and homophobia as well as lesbian sexual preference behavior.

I may not receive any direct benefit from participation in this study, but my participation may help to increase the knowledge which may benefit others in the future.

The researcher has offered to answer any questions I may have about the study and I have been assured that all information I give will be kept confidential and that the identity of all subjects will remain anonymous.

I understand that I am free to refuse to participate or to withdraw from participation in the study at any time without jeopardizing my relationship with Portland State University.

I signify that I have read the above by marking an " $x$ " on this form on the line that reads "Subject's Signature."

SUBJECT'S SIGNATURE

The witness agrees to certify that the subject has the above informed consent explained to her, and the witness observed the subject make a mark "x" upon the signature line.

WITNESS SIGNATURE 


\section{APPENDIX B \\ INDEX OF ATTITUDES TOWARD LESBIANS (IAL)}

Place the appropriate number beside each item as follows:

1. Strongly agree

2. Agree

3. Neither agree nor disagree

4. Disagree

5. Strongly disagree

1. I would feel comfortable working closely with a lesbian.

2. I would feel jealous if my spouse or partner flirted with another person.

3. I would enjoy attending social functions at which lesbians were present.

4. I would feel angry if I lost in competition to another woman.

5. I would feel uncomfortable if I learned that my neighbor were a lesbian.

6. I feel irritable when I am not physically fit.

7. I would feel angry if a member of my sex made a sexual advance toward me.

8. I feel comfortable being the center of attention at a party.

9. I would feel comfortable knowing that I was attractive to members of my own sex.

10. I feel unfeminine when I compete with a man for a job.

11. I would feel uncomfortable being in a gay bar.

12. I wouid feel uncomfortable around people who make jokes about homosexuals.

13. I would feel comfortabie if a member of my own sex made a sexuai advance toward me.

14. I feel offended if a man does not proposition me.

15. I would be comfortable if I found myself attracted to a member of my own sex.

10. I feel feminine when a man offers me an act of chivalry. 
17. I would feel ashamed if I learned that my daughter were a lesbian. 18. I feel insulted when a man makes a sexist comment.

19. I would feel nervous being in a group of lesbians.

20. I feel angry when a person tries to control me by means of intimidation.

21. I would feel comfortable knowing that a member of my clergy is a lesbian.

22. I feel nervous when I go out on a blind date.

23. I would be upset if I learned that my sister were a lesbian.

24. I feel proud when a good-looking male propositions me.

25. I feel that I had failed as a parent if I learned that my daughter were a lesbian.

26. I would feel comfortable being without an intimate relationship for a long period of time.

27. I would be offended if a woman I knew to be a lesbian complimented me on my physical appearance.

28. I feel uncomfortable when two people openly display petting in public.

29. I would feel comfortable if I learned that my daughter's teacher were a lesbian.

30. I feel repulsed by the idea of a man having sexual relations with another man.

31. I would feel comfortable if I learned that my coach were a iesbian.

32. I feel more energetic when in a group of liberated women.

33. I would feel at ease talking to a lesbian at a party.

34. I feel uncomfortable when I hear swearing and obscenity from women.

35. I would feel uncomfortable if I learned that my boss were a lesbian.

36. I feel insulted when a man with equal qualifications is given preference over me in being hired and promoted.

37. I would feel comfortable walking through a predominantly lesbian section of town. 
38. I would feel comfortable sharing my thoughts on the women's movement with a group of radical feminists.

39. I would be disturbed to find out that my doctor is a lesbian.

40. I am ashamed when I am criticized by my boss or superior.

41. I would feel disgusted if I saw two women holding hands in public.

42. I feel comfortable having sexual relations with someone before I am in love with that individual.

43. I would feel comfortable having a close friend who is a lesbian.

44. I would feel comfortable dating someone I met in a bar.

45. I would be repulsed by the thought of two women having sexual relations with each other.

46. I feel comfortable being the only woman in a group of men.

47. I would feel uncomfortable seeing two women kiss passionately.

48. I feel comfortable being dependent financially on another person.

49. I would feel flattered if a member of my sex made a sexual advance toward me.

50. I feel comfortable associating with closed minded people.

51. I would feel comfortable playing on the same sports team with a lesbian.

Reversals: $5,7,11,17,19,23,25,27,35,39,41,45,47$.

Formula for Scoring IAL: $S=\{x-30$.

Note: Even numbered items are filler items.

odd numbered items are critical items. 
APPENDIX C

DEMOGRAPHICAL AND SOCIAL VARIABLES

College Major

Occupation

Age

This is NOT a test. There are no right or wrong answers. Be assured that your responses will be kept strictly confidential. Please answer each item as accurately and honestly as possible by placing the appropriate letter for each item on your answer sheet.

1. Grade Level:
a. junior
c. freshman
e. nonapplicable
b. senior
d. sophomore

2. Partnership status:
a. single (never married
d. divorced
b. married
c. separated
e. widowed
f. living with lover, not married

3. Race/ethnic background:
a. Caucasian
b. Afro-American
c. Asian-American
d. South-Sea Is lander

e. Hispanic

f. Native American

g. Other

4. Estimated parental family or own income (per year):
a. over $\$ 100,000$
b. $\$ 50,000-99,999$
e. $\$ 10,000-14,999$
c. $\$ 20,000-49,999$
d. $\$ 15,000-19,999$
f. $\$ 5,000-9,999$
g. below $\$ 5,000$

5. While you were growing up (until approximately 18 years of age) what kind of community did you generally live in?
a. rural/farm
b. town/small city near large city
c. suburban area near large city
d. large city
e. inner city (e.g., ghetto, barrio)

6. Were you raised in the United States?
a. Yes
b. No

7. If you were not raised in the United States, where were you raised? 
8. If you were raised in the United States what area of the country?
a. Southwest
d. Southeast
b. Northwest
e. Northeast
c. Midwest

9. Were you reared in any religion?
a. Yes
b. No

10. If you were reared in a religion, which one?
a. Buddhism
b. Catholicism
d. Islam
c. Judaism
e. Protestantism
f. Other

11. Are you practicing any religion now (regular, consistent practice)?
a. Yes
b. No

12. If you are practicing a religion now, which one?
a. Buddhism
b. Catholicism
c. Judaism
d. Islam
e. Protestantism
f. Other

13. To what extent do you feel you fit this feminine stereotype (e.g., passive, tender, emotional, nurturant, dependent, weak, soft, submissive, intuitive)?
a. extremely feminine
b. moderately feminine
c. slightly feminine
d. not at all feminine

14. To what extent to you feel you fit this masculine stereotype (e.g., aggressive, competitive, dominant, controlled, self-confident, logical. adventurous, independent, ambitious)?
a. extremely masculine
c. slightly masculine
b. moderately masculine
d. not at all masculine

15. To what extent do you agree with feminism (equality between the sexes)?
a. strongly agree
d. disagree
b. agree
c. neither agree nor disagree
e. strongly disagree

16. Describe your sports involvement in elementary school:

a. competitively active

d. slightly active

b. active but not in competition e. not at all active

c. moderately active

17. Describe your sports involvement in high school:
a. competitively active
d. stightly active
b. active but not in competition e. not at all active
c. moderately active 
18. Describe your sports involvement in college:
a. competitively active
d. slightly active
b. active but not in competition e. not at all active
c. moderately active

19. If there has been a change in your sports involvement over the years, why?

20. What type of sports and physical activities do you generally prefer?

a. Individual (e.g., tennis, gymnastics, scuba diving, fishing,

hiking, biking, yoga, frisbee)

b. Team (e.g., softball, basketball, volleyball, soccer, team handball)

21. With whom do you have close personal relationships?

a. only members of the opposite sex

b. usually members of the opposite sex but occasionally members of the same sex

c. members of each sex about equally

d. usually members of the same sex but occasionally members of the opposite sex

e. only members of the same sex

f. no one

22. About whom do you have sexual fantasies?

a. only members of the opposite sex

b. usually members of the opposite sex but occasionally members of the same sex

c. members of each sex about equally

d. usually members of the same sex but occasionally members of the opposite sex

e. only members of the same sex

f. no one

23. With whom are you sexually intimate?

a. only members of the opposite sex

b. usually members of the opposite sex but occasionally members of the same sex

c. members of each sex about equaliy

d. usually members of the same sex but occasionally members of the opposite sex

e. only members of the same sex

f. no one

24. How did you first learn about sexual intimacy among women (e.g., sexuality course, book, television, movie, etc.)? 
25. To what extent have your feelings toward lesbianism changed over the past five years?

a. much more positive

b. somewhat more positive

d. somewhat more negative

c. no change

e. much more negative

26. If there has been a change in your feelings, what is the reason(s) for this change? 